\title{
Determining Tariff Seasons Based on Regional and Daily Temperature and System Load
}

\author{
Nadia zendehdel, Amin Jafari Sani \\ Quchan University of Technology
}

\begin{abstract}
In Iranian electricity tariff regulations, two tariff seasons, namely warm and non-warm seasons, to allow the government to increase the energy price in warm days as $20 \%$. This is a tariff based demand side management policy. However, the mismatch between these seasons and the reality of power system operating condition decreases this policy efficiency. So, a new approach is proposed in this paper to set these seasons online and dynamically. To this end, the days of a year are clustered independently in two groups, using K-means algorithm, once based on the daily average temperature and again based on the daily peak load. Afterward, the seasonal membership situation of a day is set based on the comparison between obtained results and the operating conditions of the power system which can be affected by the weather, accidents, and technical network limitations. To analyze the performance of the proposed approach, an industrial consumer bill is calculated with respect to the new tariff seasons and compared with the consumer's current bill. The obtained results show that the current three-time tariff has a demand response potential which depends on the dynamical definition of tariff seasons.
\end{abstract}

\section{Introduction}

Demand response is an important demand side management program. In such a program, each consumer receives motivational signals and optimizes its load profile as an active agent to improve the power system conditions. The consumer response can be more effective if the received signal is nearest to the actual power system operating condition. Today, in Iran, a three-time TOU tariff with fixed rates is used to keep dynamical electricity pricing [1]. In addition, based on the current tariff regulation, the electricity rates are $20 \%$ increased on summer day to encourage consumers to response during the critical periods of power system operation [2]. These situations are predefined on the meters and do not adapt the real condition [2]. In some region, the load profile is not matching with predefined peak load, middle load and low load times in TOU tariff. Additionally, tariff reasons are not defined correctly. So, the consumer response is failed.

A dynamical and adaptive electricity pricing is an important topic in demand side management programs, so it has received many attentions from researchers. In [1], to correct the current three-time tariff, a TOU tariff has been designed based on the regional load profile and the energy price. In this program, tariff season and three periods of time in a day has been defined in a region optimally. The critical peak pricing is an another dynamic pricing program such that the electricity rates in 400 critical hours are set ten times greater than the base price [3]. Real time pricing is another dynamic tariff which is a nearest type of pricing to the reality of the power system. In [4], such a program has been designed considering the Iranian power system characteristics and electricity market. Any consumer, who has been equipped with advanced metering infrastructure, could participate in such a program and has received its rates hourly. The RTP rates has been determined hourly, based on the supplying, distributing and transmitting cost of $1 \mathrm{Kwh}$ electricity energy in a float last three years archive. Although the mention electricity pricing strategies have been dynamic, none of them has studied on the tariff reasons definition method.

To correct the tariff reason definition method in current tariff regulation, in this study, the days of a yearly period, started from the target day, are clustered in to two groups, namely warm season and non-warm season. This classification is done once upon the daily average temperature and another one based on the regional daily peak load using K-means algorithm. In this study the Khorasan Razavi is chosen as a pilot. A day seasonal membership criteria can be defined based on obtained results of the mentioned clustering. To evaluate the proposed algorithm, an industrial consumer is selected ant its electricity bill is calculated with considering the modified tariff rates which are $20 \%$ increased in the proposed warm season. The comparison between the calculated bill and the consumer current bill shows the importance of the online definition of the warm season. In addition, the obtained results illustrate a hidden demand response potential in current tariff, which can be released if the tariff rates are as nearest as possible to the reality of the power system operating condition. 
This paper is organized as follows. In section $2, \mathrm{~K}$-means algorithm, as a clustering method, is presented. In section 3, days of 2016 are clustered in to two groups, namely warm and non-warm seasons, using the daily temperature and load profile. Furthermore, the membership criterion is defined based on the classification results. In section 4, the proposed tariff seasons are examined and numerical analysis is illustrated. Section 5 is about discussion.

\section{K-MEANS CLUSTERING METHOD}

$\mathrm{K}$-meams algorithm is a learning iterative method without supervision. During this algorithm, available data is clustered into some group based on a similarity criterion [5]. In K-means algorithm the similarity criterion is distance. The number of groups and the similarity criterion is predefined but the members of each group are changed during any iteration. At the start of the algorithm, a sample of data is chosen as centers of clusters. The points with the smallest distance to the center of a cluster belong to that cluster. If all points are clustered, an iteration of algorithm is finished. Afterward, the average of points belong to a group is calculated to replace with the group center. The next iteration of algorithm is started by using new centers. If the distance between new calculated centers and the old one is less than a specific value, the algorithm is stopped and all points are categorized in some clusters. The mentioned algorithm is illustrated with a flowchart in Fig.1.

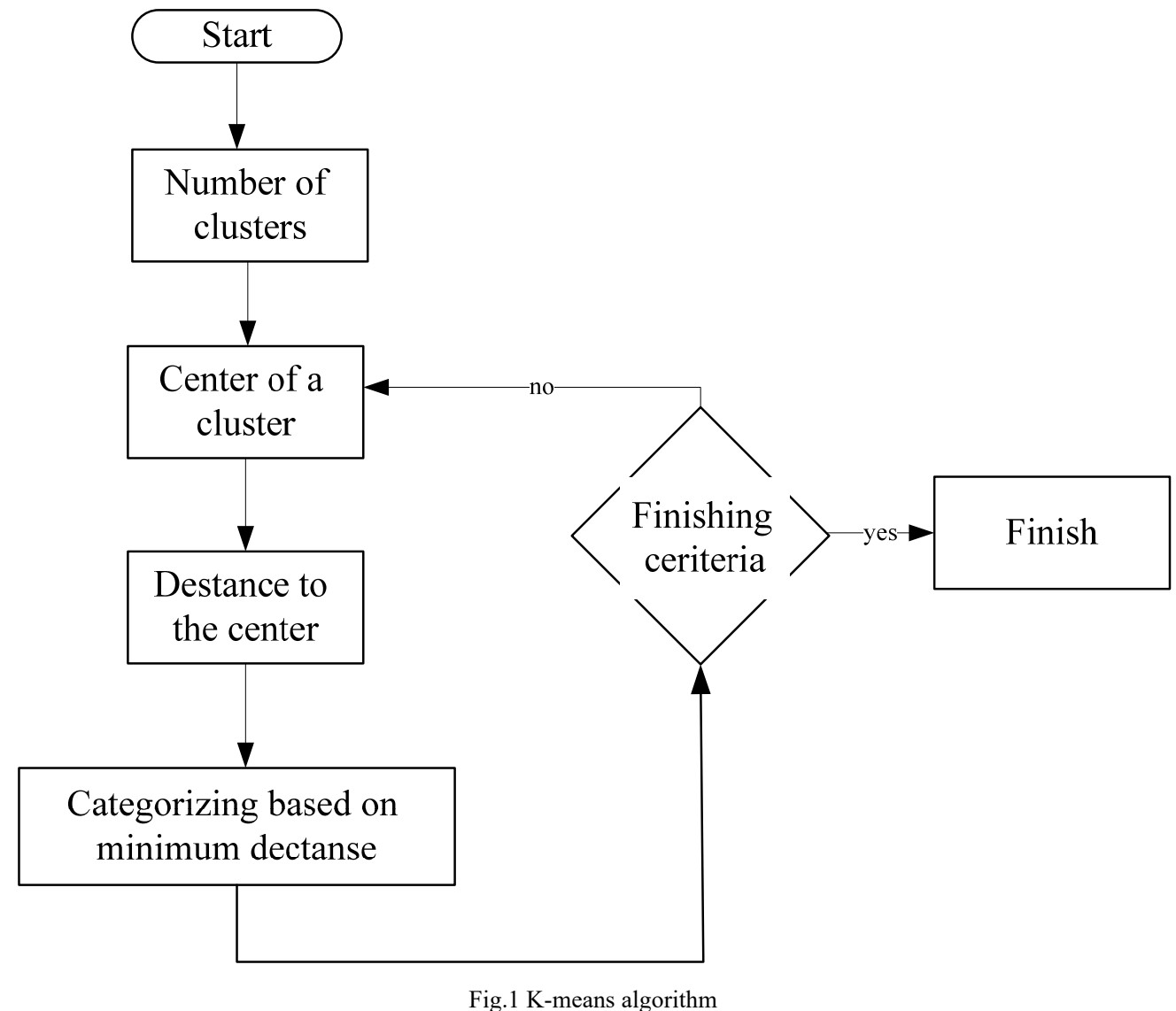

\section{TARIFF SEASON DEFINITION}

In this section, days of 2016 are categorized in two grouped namely, warm season and non-warm season, using K-means algorithm. First, these seasons are defined based on, the Khorasan Razavi daily average temperature in 2016 which is available in [6]. This information is measured in Mashhad airport meteorological station [6]. In Fig. 2, 365 days of 2016, separated in warm season and non-warm season, are shown. In this figure the average temperature of days, belong to the warm season, is shown by dark color and another ones are shown by light color. 


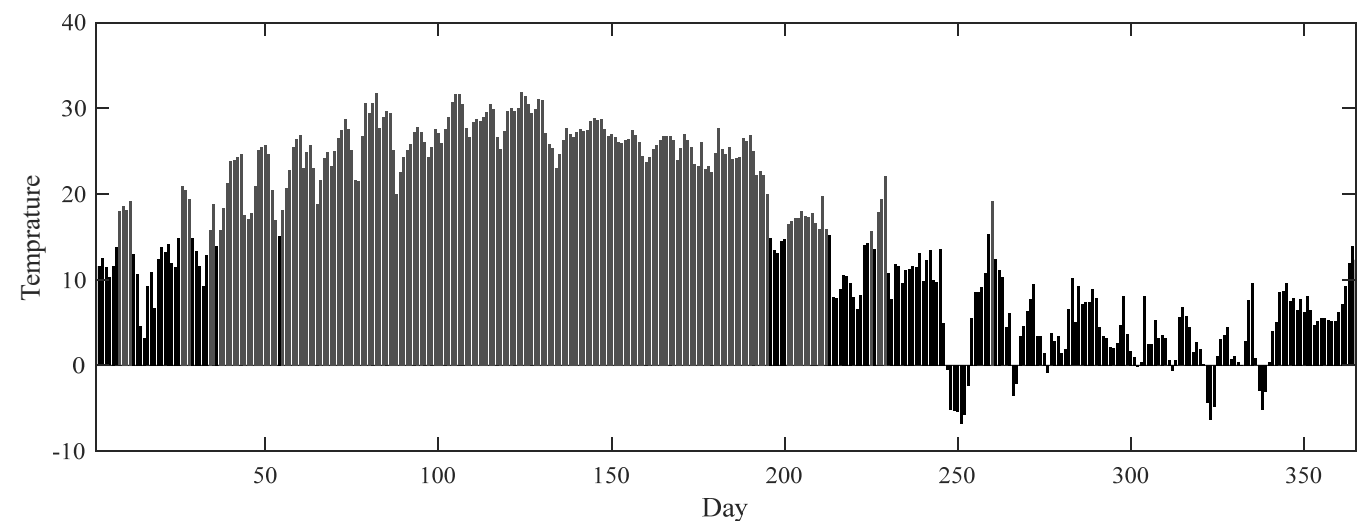

Fig. 2. The separation of days into two tariff seasons based on the average daily temperature in Khorasan Razavi

To more clarity, daily temperature and their average in non-warm season is shown in Fig. 3, separately.

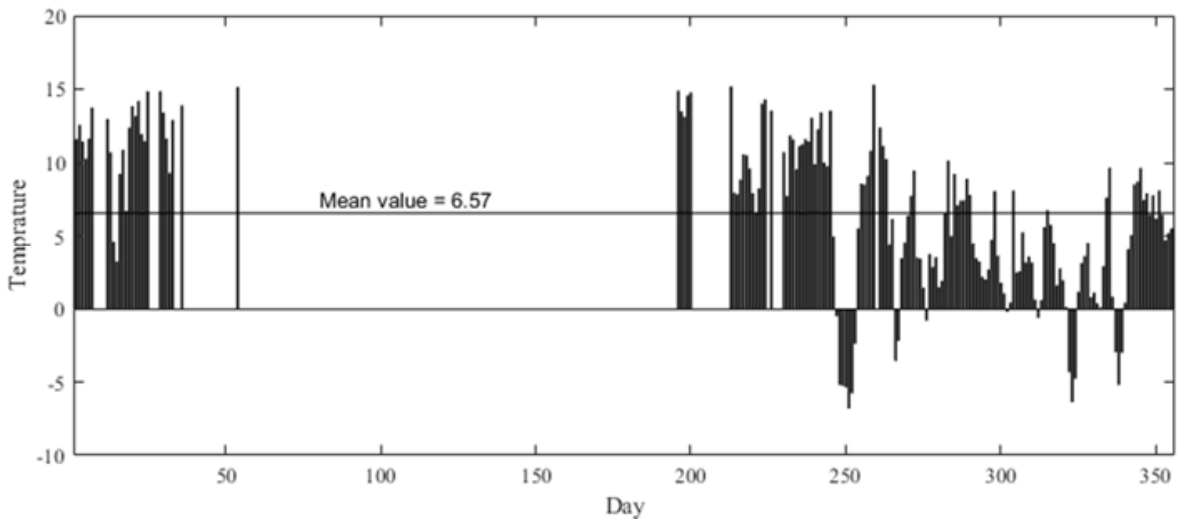

Fig. 3. Daily average temperature and the total average temperature in non-warm season

As it can be seen in Fig. 3, the average temperature in non-warm season in 2016 is equal to 6.75 degree and the $\mathrm{K}$-means algorithm converges in this point as a center of non-warm group. Unlike, a warm season in current tariff law consists of June, July and August by default. In these days, the tariff rate is $1.2 \%$ times greater than others belong to non-warm season.

Again, days of 2016 are categorized into two high load and low load seasons which are equivalent to warm and non-warm seasons respectively. To this end, maximum regional daily load of Khorasan Razavi is used. This information is available in [9]. The results are shown in figures 4 and 5.

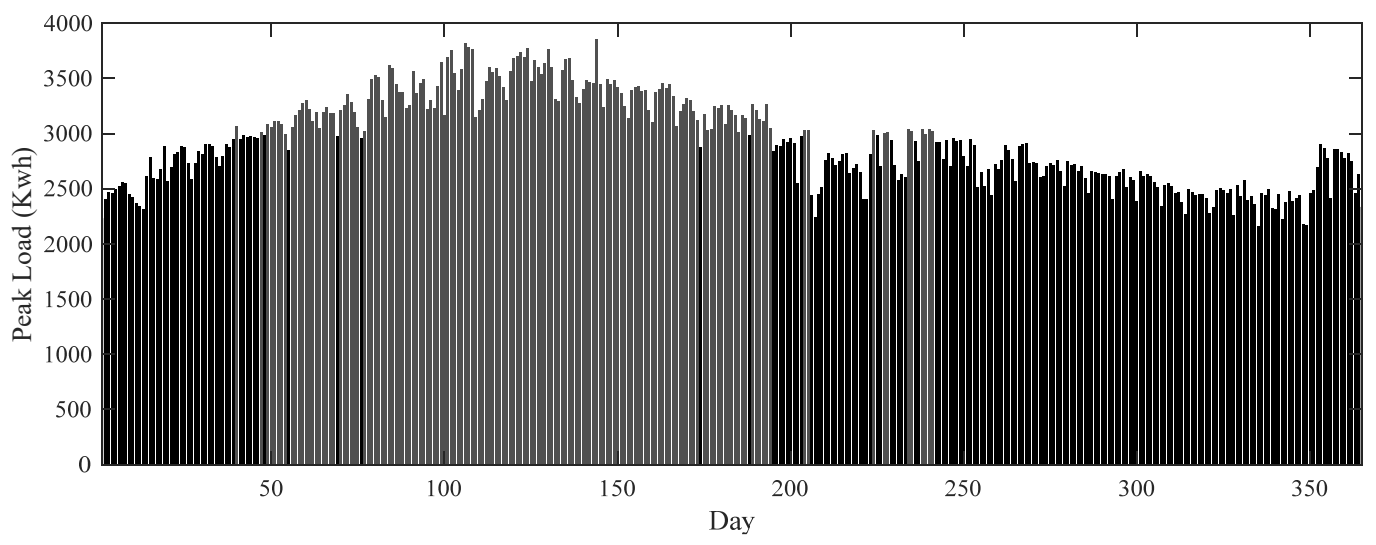

Fig. 4. The separation of days into two tariff seasons based on the maximum regional daily load of Khorasan Razavi

In Fig. 4 the load of high-load (warm) day is shown by light color. 


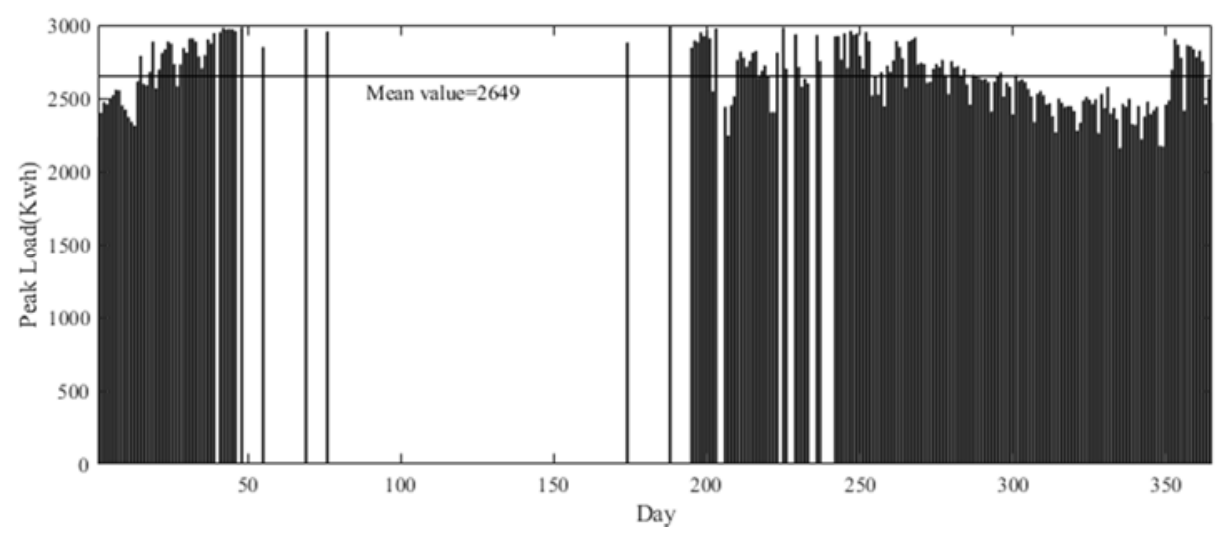

Fig. 5. Maximum load of low load (non-warm) days and their average

As it can be seen, the clustering results are different on some days. The days belong to the non-warm season and the days belong to the low load season are shown in Fig. 6 simultaneous. In this figure the amount of daily loads are shown by a light color and multiplied by 0.01 for scaling.

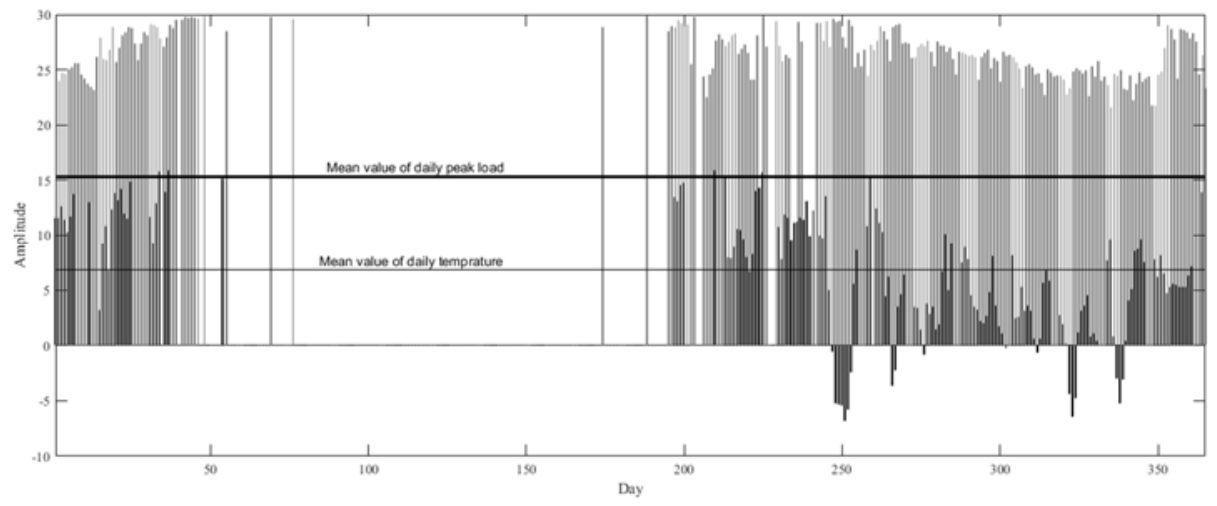

Fig. 6. The days belong to the non-warm and low load seasons

The exits differences can be related to the technical situation of power system and some social relations. For example, 11 days in March from (ie. 2016-4-26 to 2016-5-6) belong to the low load season, while the temperature is high. There exists Eid al Mab'ath, in this period of time which can change the normal load profile and increase the network demand. The power system load amounts of three days, from 2016-10-6 to 2016-10-8, have similar condition. Additionally, power system demand in these days is greater than the average seasonal load.

As it previously mentioned, the season membership criterion should be defined based on the compliance between tariff rates and the actual power system condition. So, if according to the clustering results, a day belongs to the non-warm and high load seasons, its season membership should be modified. In such day, if the maximum load is greater than the seasonal average load then the day belongs to the warm season. Otherwise the obtained results from implementing clustering algorithm on temperature information of days are accepted. Therefore, the modified tariff season in 2016 contains 45 days of the first six months and 19 days of the second six months of the year in addition to the summer season.

\section{NUMERICAL ANALYSIS}

In this section, as a pilot, an industrial consumer's bill is determined based on the proposed algorithm and compared with the current one. The consumer's load profile is selected as similar as one presented in [9]. First, an industrial consumer bill, containing the capacity and energy usage costs, is calculated based on the current industrial tariff in Iran. The capacity price in first option of 4-alef tariff code is 52378 Rial per kwh and its threetime tariff rates are illustrated in Table 1. [1,8]. 
Table 1. three-time supply consumer's tariff rates

\begin{tabular}{|l|l|l|}
\hline Energy price (Rial/Kwh) & Period & Hour \\
\hline & First six months of the year & \\
\hline 557 & Middle load & $8-21$ \\
\hline 1114 & Peak load & $20-24$ \\
\hline 278.5 & Low load & $21-8$ \\
\hline & Second six months of the year & \\
\hline 557 & Middle load & $5-17$ \\
\hline 1114 & Peak load & $17-21$ \\
\hline 278.5 & Low load & $21-5$ \\
\hline
\end{tabular}

Suppose the daily load profile is fixed over a year, the consumer bill is determined as follows. Note, in this analyze the power factor is considered as $65.7 \%$.

Table 2 . The yearly bill based on the current tariff

\begin{tabular}{|l|l|l|}
\hline & First six month of the year & Second six month of the year \\
\hline Capacity cost (Rial) & $8.2245 \times 10^{9}$ & $7.9592 \times 10^{9}$ \\
\hline Energy cost (Rial) & $2.1544 \times 10^{9}$ & $2.2183 \times 10^{9}$ \\
\hline Six month total cost & $1.0379 \times 10^{10}$ & $1.01775 \times 10^{10}$ \\
\hline Yearly bill & $2.0557 \times 10^{10}$ & \\
\hline
\end{tabular}

Second, the consumer bill is calculated considering the proposed tariff seasons. In this new bill, the energy cost is increased. Since, the proposed warm season includes some days in addition to summer days, the tariff rates are increased in more days in comparison with the current tariff. So, having the same load profile, the final energy bill is increased. In this numerical analyze the added cost is determined as $1.5108 \times 10^{9}$ Rial. This incremental cost can motivate the consumer to response and manage its consumption during the periods of time when the power system is in stress.

\section{Discussion}

In smart grids, consumers act as autonomous agents and monitor the system operating condition. If the electricity tariff and relative rules are defined as nearest as possible to the reality, the demand response program can be more effective. In this paper, the tariff seasons are corrected in an adaptive and dynamical way using Kmeans clustering method. The proposed method can be implemented regionally based on the daily average temperature and maximum load in the goal region. The proposed method is implemented on tariff rates in 2016 to calculate an industrial consumer's bill. The comparison between obtained result and the consumer's current bill shows an incremental cost which can motivate the consumer to response.

\section{References}

[1] Time of use tariff based on the regional load and energy price, Shaghaiegh yousefi, , nasrin mohadess, $29^{\text {th }}$ international power system conference. Oct 27, 2014 in NRI, Terhan.

[2] hadi modaghegh, Shaghiegh yousefi, Saboura mohammadian roshan, Nadia zendehdel, Azade emami, calculating supplying, transmitting and distributing a unit electrical energy without considering government subsidy, $31^{\text {st }}$ international power system conference. Oct 24-26, 2016 in Tehran

[3] demand response program, time of use (TOU) program and critical peak pricing (CPP) program, Energy Efficiency Organization of Iran, 2013

[4] Azade Emami, Nadia Zendehdel, Mosafa Karimpour, Hadi Modaghegh, A novel real time pricing technique for Iranian electricity market, $9^{\text {th }}$ national electric power generation, 2018.

[5] Jiawei Han, Micheline Kamber, Jian Pei, data mining. concepts and techniques, third editon, 2012 by Elsevier Inc.

[6] Available in :jira.irimo.ir:8081/irimoReportServer/login.html 